\title{
Induction of cathepsin B by the CXCR3 chemokines CXCL9 and CXCL10 in human breast cancer cells
}

\author{
HOLGER BRONGER $^{1}$, ANNE KARGE ${ }^{1}$, TOBIAS DREYER ${ }^{1}$, DANIELA ZECH ${ }^{1}$, SARA KRAEFT ${ }^{1}$, \\ STEFANIE AVRIL ${ }^{2,3}$, MARION KIECHLE ${ }^{1}$ and MANFRED SCHMITT ${ }^{1}$
}

\author{
Departments of ${ }^{1}$ Gynecology and Obstetrics and ${ }^{2}$ Pathology, Technical University of Munich, D-81675 Munich, \\ Germany; ${ }^{3}$ Department of Pathology, Case Western Reserve University School of Medicine, \\ University Hospital Case Medical Center, Cleveland, OH 44106-7288, USA
}

Received September 1, 2016; Accepted January 31, 2017

DOI: $10.3892 / 01.2017 .5994$

\begin{abstract}
Cathepsin B (CTSB) is a lysosomal cysteine protease that has been linked to the progression of breast cancer, for example by activation of other proteases and tumor-promoting cytokines, thereby supporting tumor invasion and metastasis. Previously, it was shown that CTSB cleaves and inactivates C-X-C motif chemokine receptor 3 (CXCR3) chemokines. As CXCR3 ligands have been demonstrated to induce proteases in cancer cells, the present study hypothesized that they may also affect CTSB in breast cancer cells. The results demonstrated that the human breast cancer tumor cell lines MCF-7 and MDA-MB-231 express the CXCR3 splice variants $\mathrm{A}$ and $\mathrm{B}$ and CTSB. Upon binding to CXCR3, the two chemokine ligands $\mathrm{C}-\mathrm{X}-\mathrm{C}$ motif chemokine ligand (CXCL) 9 and CXCL10 trigger upregulation of CTSB in these breast cancer cells, whereas the CXCR3-B-specific ligand CXCL4 has no such effect, suggesting the involvement of CXCR3-A in the regulation of CTSB. In early-stage human breast cancer specimens $(n=81)$, overexpression of CXCR3 is associated with statistically significant poorer overall survival, independent of lymph node status, tumor size and nuclear grading (hazard ratio $=1.99 ; 95 \%$ confidence interval $=1.00-3.97 ; \mathrm{P}=0.050)$. In conclusion, the data from the current study propose a so far unknown mechanism by which breast cancer cells may exploit tumor-suppressive chemokines to enhance their invasiveness and reduce immune cell infiltration by the degradation of these chemokines. This mechanism may support the established unfavorable prognostic feature of CXCR3 expression in breast cancer.
\end{abstract}

Correspondence to: Dr Holger Bronger, Department of Gynecology and Obstetrics, Technical University of Munich, Ismaninger Straße 22, D-81675 Munich, Germany

E-mail: holger.bronger@1rz.tum.de

Key words: breast cancer, cathepsin B, CXCR3, CTSB, survival, CXCL9, CXCL10

\section{Introduction}

Cathepsin B (CTSB) is a cysteine protease physiologically involved in lysosomal protein degradation (1). In cancer cells, CTSB may be translocated to the cell surface but also secreted in the extracellular space (2). This expression distribution lends various protumorigenic properties to CTSB in solid malignancies $(3,4)$. CTSB enhances the invasiveness of cancer cells through the degradation of extracellular matrix proteins, by cleavage and inactivation of tissue inhibitors of metalloproteinases, and by disruption of cell-cell junctions. Furthermore, CTSB may affect tumor cell proliferation, migration and apoptosis, and participates in cancer angiogenesis and chemoresistance (5).

In breast cancer mouse models, knockout of the CTSB gene resulted in retarded tumor growth and fewer lung metastases $(6,7)$. Correspondingly, previous studies on human breast cancer have revealed that CTSB tissue overexpression is a strong and statistically independent adverse prognostic factor (8-12). In previous decades, it was revealed that CTSB also participates in immunoregulatory processes, as it is involved in the lysosomal cleavage of cellular proteins, eventually leading to major histocompatibility complex presentation. Cell-surface CTSB may also protect cancer cells from cytotoxic effector molecules secreted by tumor-suppressive immune cells (13).

Another potential immune evasion mechanism results from the ability of CTSB to cleave and inactivate chemokines, including the $\mathrm{C}-\mathrm{X}-\mathrm{C}$ motif chemokine receptor 3 (CXCR3) chemokine receptor ligands $\mathrm{C}-\mathrm{X}-\mathrm{C}$ motif chemokine ligand (CXCL)9 and CXCL10 (14,15). CXCR3 is expressed by tumor-suppressive lymphocytes such as cytotoxic $\mathrm{T}$ cells and natural killer cells, mediating their infiltration into solid malignancies $(16,17)$. Cancer cells may therefore co-opt CTSB to cleave and inactivate CXCR3 ligands, which may lead to a reduced number of tumor-infiltrating lymphocytes. A similar underlying mechanism has also been demonstrated for dipeptidyl peptidase 4, which cleaves CXCR3 chemokines (18).

Therefore, the present study hypothesized that tumor cells may upregulate CTSB expression upon CXCR3 activation by employing a negative feedback mechanism, similar to the one demonstrated for the induction of matrix metalloproteinase (MMP)-9 in colon and breast cancer $(19,20)$. To the best of 
our knowledge, the current study demonstrated for the first time that the CXCR3 ligands CXCL9 and CXCL10 induce the expression and secretion of CTSB in human breast cancer cells in concert with CXCR3 overexpression.

\section{Materials and methods}

Patient characteristics. Patients with early-stage breast cancer $(n=88)$ who underwent primary surgical treatment between March 1987 and December 1991 at the Department of Gynecology and Obstetrics, Technical University of Munich (Germany) were included in the study. The present study was approved by the local ethics committee, and all patients provided written informed consent. The median duration of clinical follow-up was 112 months (range, 1-329). Patient characteristics are as follows: Median age, 59 years (range, 33-84); incidence of mortality, 55/88 patients $(63 \%)$. The tumor stages wereT1 $(22 / 88,25 \%)$, T2 $(37 / 88,42 \%)$, T3 $(11 / 88,13 \%)$, T4 $(12 / 88,14 \%)$ and unknown $(6 / 88,7 \%)$. The nuclear grading was as follows: G1 (4/88, 5\%), G2 (38/88, 43\%), G3 (25/88, $28 \%$ ) and unknown $(21 / 88,24 \%)$. The lymph node status was node-negative $(34 / 88,39 \%)$, node-positive $(47 / 88,53 \%)$ and unknown $(7 / 88,8 \%)$. The estrogen receptor- $\alpha$ statuses were as follows: Negative $(13 / 88,15 \%)$, positive $(61 / 88,69 \%)$ and unknown $(14 / 88,16 \%)$. No information regarding the human epidermal growth factor receptor 2 status was recorded. Patients received adjuvant treatment according to consensus recommendations (9).

Reagents, antibodies and cell lines. Dulbecco's modified Eagle's medium (DMEM), fetal calf serum (FCS), gentamycin, 4-(2-hydroxyethyl)-1-piperazineethanesulfonic acid (HEPES), and glutamine were obtained from Gibco (Thermo Fisher Scientific, Inc., Waltham, MA, USA). Recombinant human CXCL4/PF4 protein (CXCL4), recombinant human CXCL9/MIG protein (CXCL9) and recombinant human CXCL10/IP-10 protein (CXCL10) were from R\&D Systems, Inc. (Minneapolis, MN, USA) and were reconstituted in PBS supplemented with 5\% bovine serum albumin (A1470; Sigma-Aldrich; Merck Millipore, Darmstadt, Germany). The 7-aminoactinomycin D (7-AAD) viability staining solution was purchased from eBioscience, Inc. (catalog no. 00-6993-50; San Diego, CA, USA). All other chemicals were of analytical grade and obtained from Merck Millipore. Monoclonal antibodies to the human antigens CTSB (catalog no. MAB965; clone 73317; rat IgG1), CXCR3 (catalog no. MAB160, clone 49801, mouse IgG1) and the IgG1 isotype control antibody (catalog no. MAB002) were all purchased from R\&D Systems, Inc. Monoclonal mouse anti-GAPDH (catalog no. CB1001, clone 6C5) was obtained from EMD Millipore (Billerica, MA, USA). Alexa Fluor 488-conjugated goat anti-mouse IgG (heavy and light chains) was purchased from Thermo Fisher Scientific, Inc. (catalog no. A-11001). Horseradish peroxidase-conjugated goat anti-mouse IgG (Jackson Immuno Research Laboratories, Inc., Burlington, ON, USA). TheMDA-MB-231 and MCF-7 human breast cancer cell lines (American Type Culture Collection, Manassas, VA, USA) were cultured in a humidified $5 \% \mathrm{CO}_{2}$ atmosphere at $37^{\circ} \mathrm{C}$ in DMEM supplemented with glutamine, $10 \% \mathrm{FCS}, 10 \mathrm{mM}$ HEPES and $20 \mu \mathrm{g} / \mathrm{ml}$ gentamycin.
CXCR3 immunohistochemistry and flow cytometry. Immunohistochemistry was performed on 4- $\mu \mathrm{m}$ thick sections cut from routine formalin-fixed paraffin-embedded (FFPE)-blocks prepared from invasive breast cancer tissue specimens $(n=88)$ obtained from patients with breast cancer treated at the Department of Obstetrics and Gynecology, Medical School of the Technical University of Munich. Briefly, cut sections were deparaffinized by treatment with xylene followed by a graded series of ethanol (100-70\%) and rehydration in distilled $\mathrm{H}_{2} \mathrm{O}$, and subjected to heat-induced epitope retrieval in citrate buffer $(2.1 \mathrm{~g}$ citric acid monohydrate for 1 liter aqua dest; Sigma-Aldrich; Merck Millipore, Darmstadt, Germany), $\mathrm{pH}$ 6.0). Endogenous peroxidase activity was blocked by treatment of the sections with $3 \% \mathrm{H}_{2} \mathrm{O}_{2}$ in distilled $\mathrm{H}_{2} \mathrm{O}$ for $20 \mathrm{~min}$ at room temperature, followed by endogenous avidin/biotin block using a blocking kit (catalog no. AB972; Zytomed, Berlin, Germany), according to the manufacturer's instructions, and subsequent incubation with 5\% goat serum (Dako, Glostrup, Denmark). The sections were then incubated ( $1 \mathrm{~h}$, room temperature) with $0.5 \mu \mathrm{g} / \mathrm{ml}$ of antibody MAB160 to human CXCR3 diluted in green antibody diluent (catalog no. S2022; Dako; Agilent Technologies, Inc., Santa Clara, CA, USA). Subsequently, for detection of the primary antibody binding reaction, the LSAB-kit (Zytomed Systems, Berlin, Germany) was employed according to the manufacturer's protocol. Sections were washed thoroughly between incubations and cell nuclei were counterstained with Meyer's hematoxylin. Staining of tumor cells for CXCR3 protein expression was assessed semi-quantitatively as absent $(0)$, weak $(1+)$, moderate $(2+)$ or intense (3+) cytoplasmic staining. As tumors generally demonstrated diffuse staining of varying intensity and no considerable intra-tumoral heterogeneity, the number of positive cells was not included into the scoring algorithm. As an internal positive reference, normal fallopian tube epithelium, previously classified as $2+$ positivity for CXCR3 protein expression, was additionally stained.

To assess breast cancer cell lines for cell surface expression of CXCR3, MCF-7 and MDA-MB-231 cells were incubated with monoclonal antibody MAB160 to human CXCR3 (dilution, $1: 6.25$ in $50 \mu \mathrm{l} ; 200 \mu \mathrm{g} / \mathrm{ml}$ in $0.5 \% \mathrm{FCS}$; $0.01 \% \mathrm{NaN}_{3}$; $1 \mathrm{~h}$ on ice). Monoclonal antibody MAB002 served as the isotype control antibody in equivalent concentrations (dilution, $1: 6.25$ in $50 \mu \mathrm{l} ; 200 \mu \mathrm{g} / \mathrm{ml}$ in $0.5 \% \mathrm{FCS} ; 0.01 \% \mathrm{NaN}_{3} ; 1 \mathrm{~h}$ on ice). Subsequently, cells were incubated with Alexa Fluor 488-conjugated antibody A-11001 (dilution, 1:350; $2.85 \mu \mathrm{g} / \mathrm{ml}$ in $0.5 \% \mathrm{FCS} ; 0.01 \% \mathrm{NaN}_{3} ; 30 \mathrm{~min}$ on ice) to visualize binding of MAB160. Dead cells were excluded by simultaneous staining with propidium iodide. Fluorescence as a measure of antibody binding or 7-AAD reaction with cell nuclei was recorded using the FACSCalibur (Becton-Dickinson, Heidelberg, Germany) and histograms were evaluated and plotted using Flowing Software 2 (version 2.5.1; Turku Center of Biotechnology, Turku, Finland).

Western blot analysis. Fresh tumor samples of human breast cancer tissue were obtained during surgery, examined by a pathologist and stored in liquid nitrogen until further use. Tumor tissue homogenates and extracts were prepared as described previously (21). Protein concentrations of the tissue 
extracts were determined by applying the BCA Protein Assay kit (Pierce; Thermo Fisher Scientific, Inc.).

MCF-7 or MDA-MB-231 cells were seeded on $6 \mathrm{~cm}$ $\varnothing$ culture plates and grown to $70 \%$ confluency. Following washing in PBS, the cells were starved for $24 \mathrm{~h}$ in serum-free medium, which was renewed $30 \mathrm{~min}$ prior to the addition of the indicated stimulants (100 $\mathrm{ng} / \mathrm{ml}$ CXCL4, CXCL9 or CXCL10). The cells were incubated for $48 \mathrm{~h}$ and then washed in ice-cold PBS to be lysed in SDS-PAGE sample buffer (pH 6.0) containing $50 \mathrm{mM} \mathrm{Na} \mathrm{HPO}_{4} / \mathrm{NaH}_{2} \mathrm{PO}_{4}, 0.2 \mathrm{M} \mathrm{NaCl}$, $5 \mathrm{mM}$ EDTA and $1 \%$ Triton X-100. The lysates were chilled on ice for $20 \mathrm{~min}$ and then subjected to ultrasound treatment $\left(2 \times 10 \mathrm{sec}, 4^{\circ} \mathrm{C}\right)$ prior to storage at $-20^{\circ} \mathrm{C}$ until further use. The BCA Protein Assay kit (Pierce; Thermo Fisher Scientific, Inc.) was applied for assessment of the protein concentration of the homogenates according to the manufacturer's protocol. Equal amounts of protein $(30 \mu \mathrm{g})$ were applied to $10 \%$ SDS-PAGE as described previously (22). Blotting of the separated protein bands to a nitrocellulose membrane (Schleicher \& Schuell, Dassel, Germany) was performed by semi-dry transfer technology (Biometra, Göttingen, Germany). Blots were blocked ( $1 \mathrm{~h}$, room temperature) with PBS/0.5\% Tween 20 (w/v) (PBST) containing 5\% skimmed milk powder (Sigma-Aldrich; Merck Millipore), washed 3 times with PBST and then incubated overnight at $4^{\circ} \mathrm{C}$ with the following antibodies: MAB160 to CXCR3 $(0.67 \mu \mathrm{g} / \mathrm{ml})$, MAB965 to CTSB $(0.5 \mu \mathrm{g} / \mathrm{ml})$ in $5 \%$ bovine serum albumin/PBST, 6 C5 to GAPDH $(0.1 \mu \mathrm{g} / \mathrm{ml})$ in 5\% skimmed milk/PBST. Subsequently, the blots were washed with PBST and then incubated with horseradish peroxidase-coupled anti-mouse (for MAB160, 6C5) or anti-rat IgG (for MAB965) at room temperature for $1 \mathrm{~h}$. The blots were washed with PBST prior to antibody reaction visualization using enhanced chemiluminescence detection (GE Healthcare Life Sciences, Uppsala, Sweden). For this, the blots were exposed to CEA RP-new (Agfa HealthCare NV, Mortsel, Belgium) and developed by Cawomat 2000 IR (Cawo, Schrobenhausen, Germany). For CXCR3 western blotting, Tris-buffered saline containing $0.1 \%$ Tween 20 was used instead of PBST.

Measurement of CTSB using ELISA. Tumor cell stimulation experiments with CXCL9, CXCL10 and CXCL4 were performed as described previously (23). Briefly, MDA-MB-231 cells were plated on 12-well culture plates and grown to $70 \%$ confluency, washed with PBS and then starved for $24 \mathrm{~h}$ in serum-free medium. The serum-free medium was renewed $30 \mathrm{~min}$ prior to addition of the relevant stimulant. Supernatants were collected after $48 \mathrm{~h}$ and stored at $-20^{\circ} \mathrm{C}$ until further use. In each experiment, 8 wells were stimulated. Secretion levels of CTSB were determined by using the human CTSB Duo set ELISA kit (DY2176, R\&D Systems, Inc.), according to the manufacturer's protocol. CTSB content values determined in the respective breast cancer tumor tissues were retrieved from the tumor tissue data bank of the Department of Obstetrics and Gynecology of the Technical University of Munich.

Statistical analyses. Univariate survival analyses were performed and plotted for overall survival according to the Kaplan-Meier method (24). For multivariable survival analyses, a Cox proportional hazards model was used. Results of the cell culture stimulation experiments were assessed using mean values taken from at least three independent experiments and analyzed and employing the Mann-Whitney test (SPSS version 21.0; IBM SPSS, Armonk, NY, USA). Results are presented as the mean \pm standard error of the mean. Statistical significance was defined as $\mathrm{P} \leq 0.05, \mathrm{P} \leq 0.005$ or $\mathrm{P} \leq 0.001$. A minimum threshold of $\mathrm{P}<0.05$ was considered to indicate a statistically significant difference.

\section{Results}

CXCR3 expression in human breast cancer is associated with an adverse clinical outcome. As a prerequisite for the present study, the protein expression levels of the chemokine receptor CXCR3 were determined using immunohistochemical staining of 88 human primary invasive breast cancer FFPE-tissue sections. In these malignant tissues, CXCR3 was located in the region of tumor cells in adjacent non-malignant duct cells, lymphocytes and endothelial cells (Fig. 1A and B), confirming earlier findings by Datta et al (25) and Ma et al (26). Tumor cell CXCR3 protein expression levels were assessed semi-quantitatively as absent $(0,7 / 88)$, weak $(1+, 24 / 88)$, moderate $(2+$, $25 / 88)$ or intense $(3+, 32 / 88)$ based on cytoplasmic staining (Fig. 1C-E). The majority of tissue samples exhibited moderate to intense staining in tumor cells. Immunoblot analysis of breast cancer tissue extracts employing the same antibody as engaged in the immunohistochemical study resulted in recognition of the two splice variants CXCR3-A and CXCR3-B (Fig. 1F).

The CXCR3 protein expression levels in FFPE breast cancer tumor cells were divided into groups with low $(0,1+$; $\mathrm{n}=31)$ and high expression $(2+, 3+; n=57)$. Patients with breast cancer with high CXCR3 protein expression levels exhibited a significantly reduced median overall survival compared with the low-level group (102 vs. 217 months, hazard ratio (HR), 1.79; 95\% confidence interval (CI), 1.00-3.23; $\mathrm{P}=0.048$; Fig. 2 ). The median disease-free-survival time was also reduced (120 vs. 227 months; HR, 3.10; 95\% CI, 0.88-10.96; $\mathrm{P}=0.08$ ).

The trend in overall survival difference was greater in the node-negative disease cases (median survival, 251 (CXCR $3^{\text {low }}$ ) vs. 100 months $\left(\mathrm{CXCR} 3^{\text {high }}\right) ; \mathrm{P}=0.207$ ), compared with the node-positive cases [median survival, $112\left(\mathrm{CXCR} 3^{\text {low }}\right)$ vs. 111 months (CXCR $3^{\text {high }}$ ); $\mathrm{P}=0.088$ ], which supports initial data from Ma et al (26). Using multivariate analysis, the negative prognostic impact of CXCR3 overexpression remained independent of lymph node status, tumor size and nuclear grading (Table I). The 88 breast cancer FFPE tumor tissue specimens are part of the tissue collective assessed by Thomssen et al (9) for CTSB protein expression using ELISA. However, no significant correlation between CXCR3 protein expression levels in tumor cells assessed by immunohistochemistry and CTSB protein levels determined by ELISA was observed in the current study (data not shown).

CXCR3-directed chemokines CXCL9 and CXCL10 induce CTSB in human breast cancer cells. For demonstration of the interaction of CXCR3-directed chemokines CXCL9 and CXCL10, CXCR3 protein was initially assessed in the human breast cancer cell lines MCF-7 and MDA-MB-231. Western blot analysis revealed that the two cell lines express the splice 

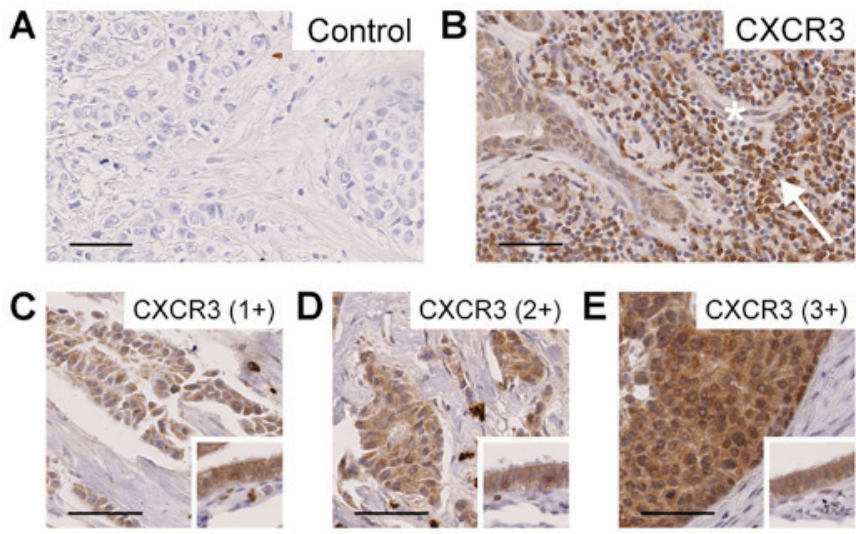

Figure 1. Protein expression of CXCR3 in human invasive ductal breast cancer formalin-fixed paraffin-embedded specimens, as evaluated by immunohistochemistry. (A) Negative control without addition of primary antibody. (B) Expression of CXCR3 in tumor-adjacent normal ductal cells, tumor-infiltrating lymphocytes (arrow) and endothelial cells (asterisk). (C-E) Various breast cancer tissues with increasing CXCR3 protein expression. Small inserts include fallopian tube epithelium as a positive control for CXCR3 protein expression. (F) Specific detection of the CXCR3 splice variants CXCR3-A and CXCR3-B by western blot analysis using MAB160 antibody in three human breast cancer tissue extracts. Scale bars, $50 \mu \mathrm{m}$. CXCR3, C-X-C motif chemokine receptor 3 .

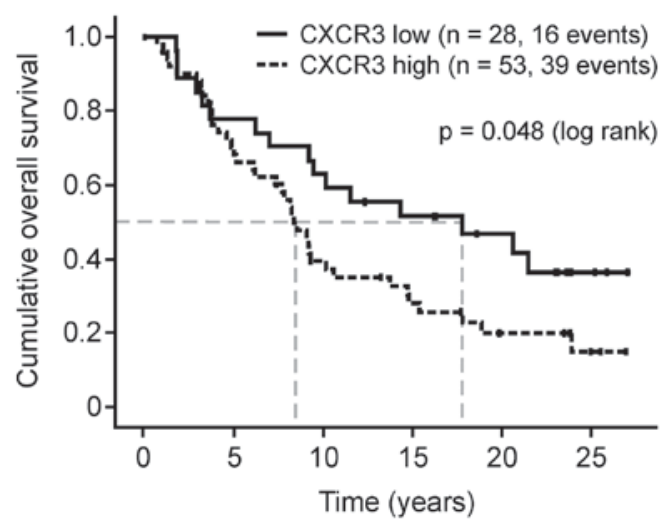

Figure 2. Reduced tumor cell CXCR3 expression in human breast cancer tissue specimens $(\mathrm{n}=81)$ is associated with increased overall survival, plotted according to the Kaplan-Meier method (24). Dashed lines indicate median time of overall survival for each of the groups. CXCR3, C-X-C motif chemokine receptor 3 .

variants CXCR3-A and CXCR3-B (Fig. 3). Although CXCR3 was identified in the cytosol of tumor cells (Fig. 1), flow cytometry analysis revealed that CXCR3 protein is also located on the cell surface of both cell lines, a prerequisite for stimulation of tumor cells by chemokines via the membrane-associated CXCR3 receptor (Fig. 3).

Subsequently, whether CXCR3 chemokines are able to induce CTSB expression in breast cancer cells was assessed, as this trend has been described for MMP-2 and MMP-9 in MDA-MB-231 cells and the colon cancer cell lines SW480, SW620, KM12C and KM12SM (19,20). Therefore, MCF-7 and MDA-MB-231 cells were incubated with $100 \mathrm{ng} / \mathrm{ml}$ recombinant CXCL9 and CXCL10, respectively. After $24 \mathrm{~h}$ (MCF-7) or $48 \mathrm{~h}$ (MDA-MB-231), cells were harvested and CTSB protein expression was evaluated by immunoblot analysis. In the two cell lines, cellular pro-CTSB $(\sim 46 \mathrm{kDa})$ and CTSB $(\sim 25 \mathrm{kDa})$ were upregulated followingCXCR3-directed chemokine exposure (Fig. 3). In this scenario, the chemokines CXCL9 and CXCL10 (100 ng/ml) significantly increased the secretion of CTSB by $\sim 1.5$ fold following $48 \mathrm{~h}$ of incubation (Fig. 3). The CXCR3-B-selective chemokine CXCL4, however, did not effect such a release, indicating that the CXCR3-A splice variant accounts for CTSB induction upon CXCL9 or CXCL10 stimulation.

\section{Discussion}

In solid malignancies, the CXCR3 chemokine receptor is a double-edged sword, as on the one hand it mediates the recruitment of tumor-suppressive lymphocytes (TILs) into the tumor microenvironment, leading to reduced tumor growth and metastatic spread associated with improved survival, but in tumor cells, CXCR3 over expression may promote cell proliferation, migration and invasion, resulting in poor clinical outcomes for patients $(27,28)$.

In breast cancer, elevated intratumoral concentrations of CXCR3 ligands are associated with enhanced numbers of TILs and improved patient survival (29-31). In syngeneic murine breast cancer models, overexpression of CXCL9 or CXCL10 leads to reduced tumor growth and lowered metastatic spread $(32,33)$. However, forced overexpression of CXCR3 in tumor cells augments pulmonary metastasis with reduced survival in these mouse models $(26,34)$. During the mammary tumorigenesis process in mice, CXCR3 is among the most upregulated genes; however, its underlying mechanisms have not yet been fully elucidated (35).

In the present breast cancer study, CXCR3 was located in tumor cells, tumor-infiltrating lymphocytes and endothelial cells, which is concordant with previous reports (25). The present findings, which reveal that CXCR3 overexpression in tumor cells is associated with significantly reduced overall survival, supports results described by Ma et al (26). In this previous study, the association of CXCR3 protein expression with unfavorable patient outcome was significant only in the node-negative subgroup. The current results are concordant with this observation; however, this effect was also seen in the node-positive subgroup. Hilborn et al (36) reported that CXCR3 protein expression in breast cancer tissue is able to predict the tamoxifen treatment response of patients, and that CXCR3 protein overexpression is correlated with reduced survival. 
Table I. Cox multivariate analysis of clinicopathological factors as well as CXCR3 expression for overall survival.

\begin{tabular}{lccc}
\hline Variable & Hazard ratio & 95\% CI & P-value \\
\hline CXCR3 expression (high vs. low) & 1.99 & $1.00-3.97$ & 0.050 \\
Nodal status (positive vs. negative) & 0.89 & $0.46-1.75$ & 0.741 \\
Tumor size (T3/4 vs. T1/2) & 2.88 & $1.53-5.45$ & 0.001 \\
Nuclear grading (G3 vs. G1/2) & 1.44 & $0.75-2.74$ & 0.272
\end{tabular}

CI, confidence interval; CXCR3, C-X-C motif chemokine receptor.
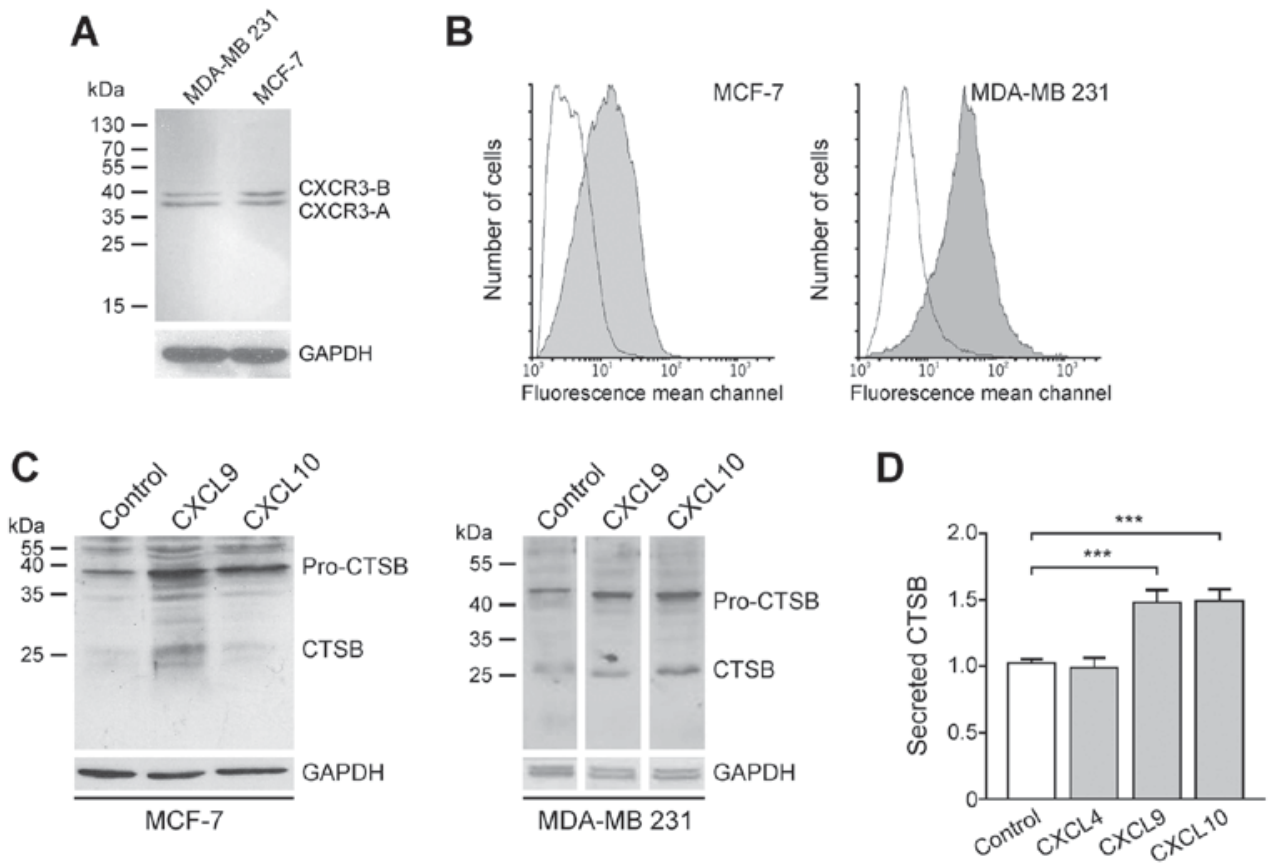

Figure 3. Induction of CTSB by CXCL9 and CXCL10 in the human breast cancer cell lines MCF-7 and MDA-MB-231. (A) These cell lines express splice variants CXCR3-A and CXCR-B as demonstrated by western blot analysis using antibody MAB160. (B) Flow cytometric detection of CXCR3 protein expression on the cell surface of living cell lines, employing antibody MAB160 (shaded curves). Solid lines, isotype control antibody. (C) Western blot analysis demonstrating induction of cellular pro-CTSB and CTSB by CXCL9 or CXCL10 in MCF-7 and MDA-MB-231 cells, using antibody MAB965. (D) Detection of CTSB in supernatants of MDA-MB-231 cells upon stimulation with CXCL9 and CXCL10, but not with CXCL4. ${ }^{* * *}$ P $\leq 0.001$ CTSB, cathepsin B; CXCL, C-X-C motif chemokine ligand; CXCR3, C-X-C motif chemokine receptor.

In the present study, to the best of our knowledge, the induction of a cysteine-type cathepsin family member, CTSB, by CXCR3 ligands in tumor cells was demonstrated for the first time. Induction of other proteases by CXCR3 ligands has been demonstrated in MDA-MB-231 breast cancer cells for the matrix metalloproteases MMP-2 and MMP-9 (19) and in the colon cancer cells SW480, SW620, KM12C and KM12SM for MMP-9 (20). In general, overexpression of proteases is linked to the enhanced invasion of tumor cells through the degradation of extracellular matrix proteins (37). Nevertheless, MMP-2 and MMP-9 may also cleave CXCR3 ligands $(38,39)$. Previously, this feature was demonstrated for CTSB and other cathepsin family members (15). Induction of these proteases, therefore, may represent a negative feedback mechanism through which cells recruited by CXCR3 ligands start to degrade the chemokine gradient immediately upon arrival at the site. Physiologically, this may limit an otherwise unregulated inflammatory reaction. Cancer cells may retain such a mechanism to increase tumor cell spread, impair CXCR3 ligands and reduce lymphocyte infiltration. Proteolytic cleavage ofCXCR3 ligands therefore may represent a protective evasion mechanism. Such a mechanism has been described for dipeptidyl peptidase IV, which also inactivates CXCL10 (18).

Induction of cysteine proteases such as CTSB by CXCR3 may explain the unfavorable clinical value of CXCR3 overexpression in breast cancer. Notably, the tumor promoting effect of CXCR3 in a syngeneic murine breast cancer model depended on IFN- $\gamma(40)$, which is one of the strongest inducers of CXCR3 ligands in breast cancer cells (23). However, the present study did not find a correlation between CXCR3 expression levels determined immunohistochemically and intratumoral CTSB concentrations as measured by ELISA by Thomssen et al (9). This may also be explained by other mechanisms contributing to CTSB expression in breast cancer.

In conclusion, CTSB is induced by CXCR 3 ligands in human breast cancer cells, which represents another underlying mechanism contributing to the negative prognostic impact of 
CXCR3 in breast cancer cells. The present findings suggest that breast cancer cells may exploit originally tumor-suppressive CXCR3 chemokines to enhance their invasiveness and reduce immune infiltration through the degradation of these chemokines.

\section{Acknowledgements}

The authors would like to thank Joachim Hornung, Elisabeth Schüren and Alexandra Stöckel (Department of Gynecology and Obstetrics, Technical University of Munich) for excellent technical assistance. This study was supported by grants from the Wilhelm Sander-Stiftung (grant nos. 2011.006.1 and 2011.006.2) to Holger Bronger, Stefanie Avril and Manfred Schmitt. Stefanie Avril is supported by the Clinical and Translational Science Collaborative of Cleveland (grant no. KL2TR000440) from the National Center for Advancing Translational Sciences component of the National Institutes of Health and NIH roadmap for Medical Research.

\section{References}

1. Yan S and Sloane BF: Molecular regulation of human cathepsin B: Implication in pathologies. Biol Chem 384: 845-854, 2003

2. Roshy S, Sloane BF and Moin K: Pericellular cathepsin B and malignant progression. Cancer Metastasis Rev 22: 271-286, 2003.

3. Aggarwal N and Sloane BF: Cathepsin B: Multiple roles in cancer. Proteomics Clin Appl 8: 427-437, 2014.

4. Olson OC and Joyce JA: Cysteine cathepsin proteases: Regulators of cancer progression and therapeutic response. Nat Rev Cancer 15: 712-729, 2015.

5. Kos J, Mitrović A and Mirković B: The current stage of cathepsin B inhibitors as potential anticancer agents. Future Med Chem 6: 1355-1371, 2014.

6. Vasiljeva O, Korovin M, Gajda M, Brodoefel H, Bojic L, Krüger A, Schurigt U, Sevenich L, Turk B, Peters C and Reinheckel T: Reduced tumour cell proliferation and delayed development of high-grade mammary carcinomas in cathepsin B-deficient mice. Oncogene 27: 4191-4199, 2008.

7. Vasiljeva O, Papazoglou A, Krüger A, Brodoefel H, Korovin M, Deussing J, Augustin N, Nielsen BS, Almholt K, Bogyo M, et al: Tumor cell-derived and macrophage-derived cathepsin B promotes progression and lung metastasis of mammary cancer. Cancer Res 66: 5242-5250, 2006.

8. Lah TT, Cercek M, Blejec A, Kos J, Gorodetsky E, Somers R and Daskal I: Cathepsin B, a prognostic indicator in lymph node-negative breast carcinoma patients: Comparison with cathepsin D, cathepsin L, and other clinical indicators. Clin Cancer Res 6: 578-584, 2000

9. Thomssen C, Schmitt M, Goretzki L, Oppelt P, Pache L, Dettmar P, Jänicke F and Graeff $\mathrm{H}$ : Prognostic value of the cysteine proteases cathepsins B and cathepsin L in human breast cancer. Clin Cancer Res 1: 741-746, 1995

10. Maguire TM, Shering SG, Duggan CM, McDermott EW, O'Higgins NJ and Duffy MJ: High levels of cathepsin B predict poor outcome in patients with breast cancer. Int J Biol Markers 13: 139-144, 1998

11. Foekens JA, Kos J, Peters HA, Krasovec M, Look MP, Cimerman N, Meijer-van Gelder ME, Henzen-Logmans SC, van Putten WL and Klijn JG: Prognostic significance of cathepsins $\mathrm{B}$ and $\mathrm{L}$ in primary human breast cancer. J Clin Oncol 16: 1013-1021, 1998

12. Harbeck N, Alt U, Berger U, Krüger A, Thomssen C, Jänicke F, Höfler H, Kates RE and Schmitt M: Prognostic impact of proteolytic factors (urokinase-type plasminogen activator, plasminogen activator inhibitor 1 , and cathepsins B, D, and L) in primary breast cancer reflects effects of adjuvant systemic therapy. Clin Cancer Res 7: 2757-2764, 2001.

13. Balaji KN, Schaschke N, Machleidt W, Catalfamo M and Henkart PA: Surface cathepsin B protects cytotoxic lymphocytes from self-destruction after degranulation. J Exp Med 196: 493-503, 2002.
14. Hasan L, Mazzucchelli L, Liebi M, Lis M, Hunger RE, Tester A, Overall CM and Wolf M: Function of liver activation-regulated chemokine/CC chemokine ligand 20 is differently affected by cathepsin B and cathepsin D processing. J Immunol 176: 6512-6522, 2006.

15. Repnik U, Starr AE, Overall CM and Turk B: Cysteine cathepsins activate ELR chemokines and inactivate non-ELR chemokines. J Biol Chem 290: 13800-13811, 2015.

16. Chen DS and Mellman I: Oncology meets immunology: The cancer-immunity cycle. Immunity 39: 1-10, 2013.

17. Wendel M, Galani IE, Suri-Payer E and Cerwenka A: Natural killer cell accumulation in tumors is dependent on IFN-gamma and CXCR3 ligands. Cancer Res 68: 8437-8445, 2008.

18. Barreira da Silva R, Laird ME, Yatim N, Fiette L, Ingersoll MA and Albert ML: Dipeptidylpeptidase 4 inhibition enhances lymphocyte trafficking, improving both naturally occurring tumor immunity and immunotherapy. Nat Immunol 16: 850-858, 2015.

19. Shin SY, Nam JS, Lim Y and Lee YH: TNF $\alpha$-exposed bone marrow-derived mesenchymal stem cells promote locomotion of MDA-MB-231 breast cancer cells through transcriptional activation of CXCR3 ligand chemokines. J Biol Chem 285: 30731-30740, 2010.

20. Zipin-Roitman A, Meshel T, Sagi-Assif O, Shalmon B, Avivi C, Pfeffer RM, Witz IP and Ben-Baruch A: CXCL10 promotes invasion-related properties in human colorectal carcinoma cells. Cancer Res 67: 3396-3405, 2007.

21. Jänicke F, Pache L, Schmitt M, Ulm K, Thomssen C, Prechtl A and Graeff $\mathrm{H}$ : Both the cytosols and detergent extracts of breast cancer tissues are suited to evaluate the prognostic impact of the urokinase-type plasminogen activator and its inhibitor, plasminogen activator inhibitor type 1. Cancer Res 54: 2527-2530, 1994.

22. Bronger H, König J, Kopplow K, Steiner HH, Ahmadi R, Herold-Mende C, Keppler D and Nies AT: ABCC drug efflux pumps and organic anion uptake transporters in human gliomas and the blood-tumor barrier. Cancer Res 65: 11419-11428, 2005.

23. Bronger H, Kraeft S, Schwarz-Boeger U, Cerny C, Stöckel A, Avril S, Kiechle M and Schmitt M: Modulation of CXCR3 ligand secretion by prostaglandin E2 and cyclooxygenase inhibitors in human breast cancer. Breast Cancer Res 14: R30, 2012.

24. Kaplan EL and Meier P: Nonparametric estimation from incomplete observations. J Amer Statist Assn 53: 457-481, 1958.

25. Datta D, Flaxenburg JA, Laxmanan S, Geehan C, Grimm M, Waaga-Gasser AM, Briscoe DM and Pal S: Ras-induced modulation of CXCL10 and its receptor splice variant CXCR3-B in MDA-MB-435 and MCF-7 cells: Relevance for the development of human breast cancer. Cancer Res 66: 9509-9518, 2006.

26. Ma X, Norsworthy K, Kundu N, Rodgers WH, Gimotty PA, Goloubeva O, Lipsky M, Li Y, Holt D and Fulton A: CXCR3 expression is associated with poor survival in breast cancer and promotes metastasis in a murine model. Mol Cancer Ther 8: 490-498, 2009.

27. Cerny C, Bronger H, Davoodi M, Sharma S, Zhu L, Obana S, Sharma J, Ebrahimi R, St John M, Lee JM, et al: The role of CXCR3/ligand axis in cancer. International Trends in Immunity 3: 46-52, 2015.

28. Ma B, Khazali A and Wells A: CXCR3 in carcinoma progression. Histol Histopathol 30: 781-792, 2015.

29. Denkert C, Loibl S, Noske A, Roller M, Müller BM, Komor M, Budczies J, Darb-Esfahani S, Kronenwett R, Hanusch C, et al: Tumor-associated lymphocytes as an independent predictor of response to neoadjuvant chemotherapy in breast cancer. J Clin Oncol 28: 105-113, 2010.

30. Denkert C, von Minckwitz G, Brase JC, Sinn BV, Gade S, Kronenwett R, Pfitzner BM, Salat C, Loi S, Schmitt WD, et al: Tumor-infiltrating lymphocytes and response to neoadjuvant chemotherapy with or without Carboplatin in human epidermal growth factor receptor 2-positive and triple-negative primary breast cancers. J Clin Oncol 33: 983-991, 2015.

31. Specht K, Harbeck N, Smida J, Annecke K, Reich U, Naehrig J, Langer R, Mages J, Busch R, Kruse E, et al: Expression profiling identifies genes that predict recurrence of breast cancer after adjuvant CMF-based chemotherapy. Breast Cancer Res Treat 118: 45-56, 2009.

32. Dorsey R, Kundu N, Yang Q, Tannenbaum CS, Sun H, Hamilton TA and Fulton AM: Immunotherapy with interleukin-10 depends on the CXC chemokines inducible protein-10 and monokine induced by IFN-gamma. Cancer Res 62: 2606-2610, 2002. 
33. Walser TC, Ma X, Kundu N, Dorsey R, Goloubeva O and Fulton AM: Immune-mediated modulation of breast cancer growth and metastasis by the chemokine Mig (CXCL9) in a murine model. J Immunother 30: 490-498, 2007.

34. Walser TC, Rifat S, Ma X, Kundu N, Ward C, Goloubeva O, Johnson MG, Medina JC, Collins TL and Fulton AM: Antagonism of CXCR3 inhibits lung metastasis in a murine model of metastatic breast cancer. Cancer Res 66: 7701-7707, 2006.

35. Yang J, Mani SA, Donaher JL, Ramaswamy S, Itzykson RA, Come C, Savagner P, Gitelman I, Richardson A and Weinberg RA: Twist, a master regulator of morphogenesis, plays an essential role in tumor metastasis. Cell 117: 927-939, 2004.

36. Hilborn E, Sivik T, Fornander T, Stål O, Nordenskjöld B and Jansson A: C-X-C ligand 10 and $\mathrm{C}-\mathrm{X}-\mathrm{C}$ receptor 3 status can predict tamoxifen treatment response in breast cancer patients. Breast Cancer Res Treat 145: 73-82, 2014.
37. Wolf $\mathrm{K}$ and Friedl P: Mapping proteolytic cancer cell-extracellular matrix interfaces. Clin Exp Metastasis 26: 289-298, 2009.

38. Van den Steen PE, Husson SJ, Proost P, Van Damme J and Opdenakker G: Carboxyterminal cleavage of the chemokines MIG and IP-10 by gelatinase B and neutrophil collagenase. Biochem Biophys Res Commun 310: 889-896, 2003.

39. Denney H, Clench MR and Woodroofe MN: Cleavage of chemokines CCL2 and CXCL10 by matrix metalloproteinases-2 and -9: Implications for chemotaxis. Biochem Biophys Res Commun 382: 341-347, 2009.

40. Zhu G, Yan HH, Pang Y, Jian J, Achyut BR, Liang X, Weiss JM, Wiltrout RH, Hollander MC and Yang L: CXCR3 as a molecular target in breast cancer metastasis: Inhibition of tumor cell migration and promotion of host anti-tumor immunity. Oncotarget 6: 43408-43419, 2015. 